\title{
Commentary: Are pediatric aortic leaflet reconstructions a long run for a short slide or a home run?
}

\author{
Aaron Eckhauser, MD, MS
}

\author{
From Division of Cardiothoracic Surgery, Department of Surgery, Pediatric Cardiothoracic Surgery, University of \\ Utah, Salt Lake City, Utah. \\ Disclosures: Author has nothing to disclose with regard to commercial support. \\ Received for publication Oct 10, 2019; revisions received Oct 10, 2019; accepted for publication Oct 10, 2019; \\ available ahead of print Nov 14, 2019. \\ Address for reprints: Aaron Eckhauser, MD, MS, 100 N Mario Capecchi Dr, Suite 2200, Salt Lake City, UT 84113 \\ (E-mail: Aaron.eckhauser@hsc.utah.edu). \\ J Thorac Cardiovasc Surg 2020;159:2379 \\ $0022-5223 / \$ 36.00$ \\ Copyright (c) 2019 by The American Association for Thoracic Surgery \\ https://doi.org/10.1016/j.jtcvs.2019.10.055
}

In this issue of the Journal, Wiggins and colleagues ${ }^{1}$ present $^{-}$ their work studying the utility of aortic valve leaflet reconstruction in children and young adults with aortic valve disease. Using data from a high-volume, single center, the authors studied 58 patients over a 4-year period who underwent either an aortic valve neo-tricuspidization procedure (Ozaki) or a single-leaflet reconstruction. The authors found that these 2 techniques can be performed safely with acceptable short-term hemodynamics in a population of patients that remains a significant clinical challenge. Although this contemporary cohort is limited by a short follow-up, there is much to be gleaned from their ongoing experience.

Broadly speaking, there has been quite a rapid evolution of new and refined aortic valve repair techniques in cardiac surgery. Out of both clinical necessity and a desire to innovate, some of these techniques have been (over)eagerly adopted from the adult to pediatric practice without robust clinical experience or rigorous study. One of the strengths of the current study is the measured approach employed to explore the efficacy and safety of only 2 reconstructive techniques in children and young adults with aortic valve disease. The study cohort consisted of patients with borderline aortic annular dimensions (preventing implantation of an adequate adult-sized prosthesis) and those who, for various reasons, were not ideally suited for a Ross procedure. The authors found that, in experienced hands, aortic leaflet reconstruction is safe with acceptable short-term hemodynamics. Their main composite outcome was a freedom from reoperation and/or $\geq$ moderate or greater aortic regurgitation at 1, 2, and 3 years of $94 \%$, $85 \%$, and $79 \%$, respectively, which compares favorably with other contemporary series. ${ }^{2}$ A similarly important finding is that there was no significant progression of aortic stenosis over the study period regardless of the reconstructive material chosen for repair. surgical treatment.

\section{References}

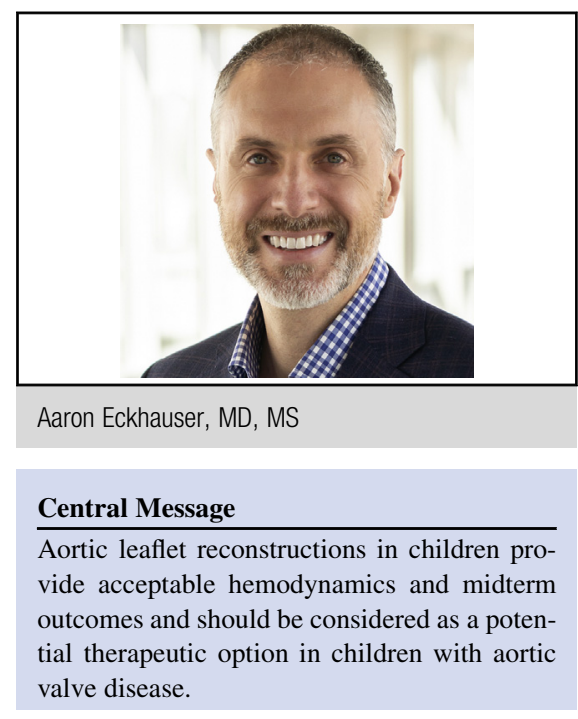

See Article page 2369.

These excellent results, however, should be regarded with cautious optimism. The median follow-up period was only 14 months, which is simply too short to understand mid- and long-term durability and outcomes. As the authors suggest, there are significant confounding variables that affect the long-term durability of these repairs, including what the optimal reconstructive material and fixation times are, and the role of exaggerated leaflet height and coaptation. In addition, there was a high rate of reoperation (12\% of patients) and endocarditis (5\% of patients) within a short study period, which require further inquiry to determine whether these are an aberration or legitimate concern.

Despite the study limitations, this excellent paper supports the selective role of aortic valve leaflet reconstruction in pediatric patients with aortic valve disease. When properly chosen, these reconstructive techniques can be deployed to support patients' safely until they are of an adequate size or anatomic substrate for a more definitive

1. Wiggins LM, Mimic B, Issitt R, Ilie S, Bonello B, Marek J, et al. The utility of aortic valve reconstruction techniques in children and young adults. J Thorac Cardiovasc Surg. 2020;159:2369-78.

2. Vergnat M, Asfour B, Arenz C, Suchowerskyj P, Bierbach B, Schindler E, et al. Contemporary results of aortic valve repair for congenital disease: lessons for management and stage strategy. Eur J Cardiothorac Surg. 2017;52:581-7. 